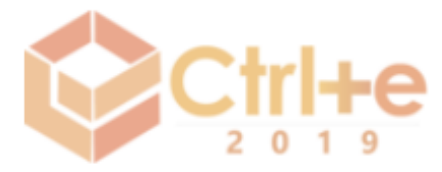

\title{
A Relação entre a Ludicidade e a Cognição em um Jogo para o Controle Inibitório
}

\author{
Ariane N. Rodrigues, Arianne S. Torcate, Claudimara C. Santos \\ Universidade de Pernambuco (UPE) - Garanhuns/PE \\ \{ariane.rodrigues, claudimara.chiste\}@upe.br, ariannesarmento0@gmail.com
}

\begin{abstract}
The article presents a game to work on inhibitory control as one of the components of executive functions important for learning. Associated with a research of conclusion of a course of Degree in Computing, the game relates the perspectives of Psychology and Computing, under the guidance of specialists of the areas. The article emphasizes the importance of playfulness with special events and its relation with the learning objectives of the game to activate appropriate cognitive processes as a strategy to stimulate behaviors associated with this executive function.
\end{abstract}

Resumo. $O$ artigo apresenta um jogo para trabalhar o controle inibitório, como um dos componentes das funções executivas importante para a aprendizagem. Associado a uma pesquisa de conclusão de um curso de Licenciatura em Computação, o jogo relaciona as perspectivas da Psicologia e Computação, e foi desenvolvido sob orientação de especialistas das áreas. $O$ artigo enfatiza a importância da ludicidade com eventos especiais e sua relação com os objetivos do jogo para ativar processos cognitivos adequados como estratégia para estimular comportamentos associados a esta função executiva durante a interação.

\section{Introdução}

Encontrar formas de intervir pedagogicamente junto a crianças e adolescentes com dificuldade de aprendizagem é um desafio constante na área Educação. A formulação de queixas escolares tem aumentado nos últimos anos, incluindo encaminhamentos a serviços especializados (CUNHA et al., 2016). Atividades lúdicas são potentes aliadas na aprendizagem e pesquisas com jogos eletrônicos apontam para sua eficácia. Ramos e Rocha (2016) realizaram uma intervenção com 50 crianças entre 8 e 11 anos utilizando este recurso e deduziram que, entre os participantes investigados, os jogos eletrônicos favoreceram o exercício de habilidades cognitivas.

O escopo teórico deste trabalho é a Psicologia Cognitiva que, segundo Sternberg (2000, p. 22), investiga o modo "como as pessoas, percebem, aprendem, recordam e pensam sobre a informação". A análise dos processos, nesta perspectiva, não se dá apenas em relação à entrada e saída das informações, mas inclui o papel das operações mentais complexas e é chamado de processamento da informação. Aliada a esta epistemologia, também embasa o desenvolvimento do jogo aqui apresentado a 
Neurociência Cognitiva, que é considerada como "[...] uma combinação de métodos de uma variedade de campos - biologia celular, neurociências da imagem, neuroimagem, psicologia cognitiva, neurologia comportamental e ciência computacional" (KANDEL et al., 2003, p. 382). Para os autores, muitos comportamentos são aprendidos, mas nem todos são benéficos ao ser humano, podendo ser disfuncionais ou proporcionar alterações psicológicas pouco saudáveis. O desenvolvimento de jogos, desta forma, precisa ser realizado considerando as possíveis influências nos processos psicológicos. Baum e Maraschin (2017), por exemplo, apresentam evidências sobre as aprendizagens possíveis relacionadas a videogames, direcionando o olhar para a interação entre o jogo e o sujeito que joga.

Dentre todas as possibilidades que a Psicologia Cognitiva e a Neurociência Cognitiva apresentam, o recorte utilizado para o desenvolvimento do jogo se situa nos estudos das Funções Executivas (FE) que, para Malloy-Diniz et al. (2012), possibilitam ao indivíduo integrar processos cognitivos de forma a direcionar comportamentos a metas, avaliando e adequando conforme o contexto. Não há um consenso na literatura sobre quais são as principais FE. Para Cerqueira et al. (2018), as FE referem-se ao grupo inter-relacionado de habilidades cognitivas que servem para regular e controlar o comportamento humano.

Na presente pesquisa, será utilizada a classificação de Seabra et al. (2014), que elencam entre as mais gerais a memória de trabalho, planejamento, flexibilidade cognitiva e controle inibitório. Segundo Malloy-Diniz (2010), déficits nas FE são frequentemente verificados em indivíduos com comprometimentos nos circuitos neurológicos pré-frontais. Segundo os autores, dificuldades nestes domínios podem ocasionar problemas em relação à adaptação social, à organização de atividades diárias e ao controle emocional. Alterações nessas funções estão relacionadas a distúrbios como o Transtorno de Déficit de Atenção e Hiperatividade (TDAH). Entender as alterações no funcionamento executivo das crianças com TDAH, na aprendizagem é um aspecto que merece ser mais discutido, pois, a maioria das pesquisas destacam aspectos comportamentais. Sob a perspectiva da concepção de jogos para este contexto, entendese que conhecer as funções executivas é uma maneira de conhecer as limitações do processo cognitivo.

Neste contexto, esta pesquisa destaca o jogo "Candy Night" que tem como objetivo trabalhar o controle inibitório. O controle inibitório pode ser definido como "...habilidade de controlar comportamentos inapropriados, assim como os processos de atenção e os pensamentos" (SEABRA et al., 2014, p. 43). O jogo aposta em eventos especiais envolvendo situações de controle do personagem como "esperar e parar". Esta estratégia é uma forma de promover a ludicidade alinhado ao objetivo de fazer com que o jogador consiga controlar os impulsos, planejar e executar as ações adequadamente. Para Araújo et al. (2016), a ludicidade deve favorecer o alcance dos objetivos do jogo, e por isso, a escolha adequada de implicações de design para sua interface é importante porque contribui na ativação dos processos cognitivos.

Este artigo possui quatro seções e está estruturado da seguinte forma: a seção 2 apresenta trabalhos relacionados ao contexto da pesquisa, a Seção 3 e seus subtópicos apresentam os detalhes do jogo, como os objetivos, aspectos lúdicos e os processos cognitivos. A Seção 4 descreve as considerações finais. 


\section{Trabalhos Relacionados}

Esta seção apresenta pesquisas que estão diretamente relacionadas ao contexto do uso de jogos digitais direcionados ao trabalho das funções executivas. A revisão da literatura apresentada por Cerqueira et al. (2018), no intervalo de 2013 a 2018, destaca a análise de jogos digitais voltados para funções executivas. A pesquisa filtra e destaca cinco jogos (Focus Pocus, Braingame Brian, Dresden Cruiser, Avioncito e Fly the Plane). A aplicação deles se concentra em considerar o controle inibitório, memória de trabalho, flexibilidade cognitiva ou para a suas respectivas estimulações. Como resultado, Cerqueira et al. (2018) expõem quais foram as habilidades cognitivas trabalhadas em cada jogo juntamente com as informações necessárias sobre os jogadores e o período de aplicação.

A pesquisa de Ramos e Anastácio (2018) destaca como os jogos digitais podem contribuir para o desenvolvimento das habilidades cognitivas no contexto escolar. A pesquisa envolveu 50 crianças de duas turmas do ensino fundamental e apresenta os resultados da aplicação dos jogos Conectome, Genius e Joaninha, da Escola do Cérebro. Com cenários e desafios diferentes, cada jogo busca maneiras diversas para inserir as habilidades cognitivas. A narrativa das crianças e os desenhos sobre o que mais foi significativo durante o uso dos jogos foram as estratégias consideradas para análise desta pesquisa. Como resultado, Ramos e Anastácio (2018), expõem que as principais habilidades cognitivas despertadas e trabalhadas com os jogos foram controle inibitório, resolução de problemas, atenção e memória.

A pesquisa de Freire et al. (2018) destaca o desenvolvimento de jogos digitais mobiles para TDAH, Dislexia e Autismo e destaca Digital Game Based Learning (DGBL) como estratégia para o processo de aprendizado que também favorece no tratamento. Os autores apresentam o desenvolvimento de dois jogos gratuitos. Um deles é "As aventuras de Ifinho" que é composto por 4 jogos, sendo eles: "Soletrando com as nuvens" para auxiliar crianças com dislexia, "Cuidado com o caçador" para crianças com TDAH, "Pegar lixo" com foco na atenção seletiva e "O que é isso?" para crianças com dislexia. O segundo jogo, ainda em fase de desenvolvimento, chama-se "Dia-a-dia com Ifinho" e tem como objetivo auxiliar no processo de aprendizagem de crianças autistas. Ele também é composto por minigames: "Objetos Iguais", "Reconheça o Áudio", "Arraste e Preencha", "Reconheça a Emoção", "Cores iguais" e "QuebraCabeça". Estes jogos foram disponibilizados para teste para verificar sua utilidade e a aplicabilidade envolveu um grupo de crianças diagnosticadas com TDAH ou Dislexia.

As pesquisas apresentadas reforçam a necessidade e importância de explorar ainda mais este contexto. Sob a perspectiva do desenvolvimento de jogos, acredita-se que deve haver rigor ao estabelecer o processo de concepção com testes e métodos específicos que possam comprovar a sua eficácia. A exploração livre de softwares similares é uma atividade que pode contribuir para o desenvolvimento do jogo apresentado neste artigo. No entanto, o acesso aos jogos citados não pôde ser realizado porque eles não foram localizados, nem disponibilizados pelos autores.

\section{Jogo Candy Night}

Esta seção descreve detalhes de um jogo, em desenvolvimento, que relaciona estratégias para inibir comportamentos associados à ausência do controle inibitório, um dos componentes da função executiva. O desenvolvimento do jogo é orientado por duas 
profissionais especializadas nas áreas de Computação e Psicologia. A seção 3.1 apresenta detalhes do jogo como cenário e personagens. A seção 3.2 apresenta os objetivos do jogo que dão base à sua concepção e a relação com os processos cognitivos. E, a seção 3.3 apresenta a relação da ludicidade com eventos que favorecem a ativação dos processos cognitivos.

\subsection{O jogo}

O jogo1 está sendo desenvolvido na ferramenta Construct 2 e possui o formato de plataforma. É indicado para crianças com faixa etária a partir de 8 anos. Ele faz referência ao Halloween, também conhecido como Dia das Bruxas. Neste caso, todo o cenário e os personagens remetem a data, a tradição de pegar doces, realizar travessuras, e assombrar as pessoas. A Figura 1 apresenta o cenário do jogo e alguns de seus personagens.
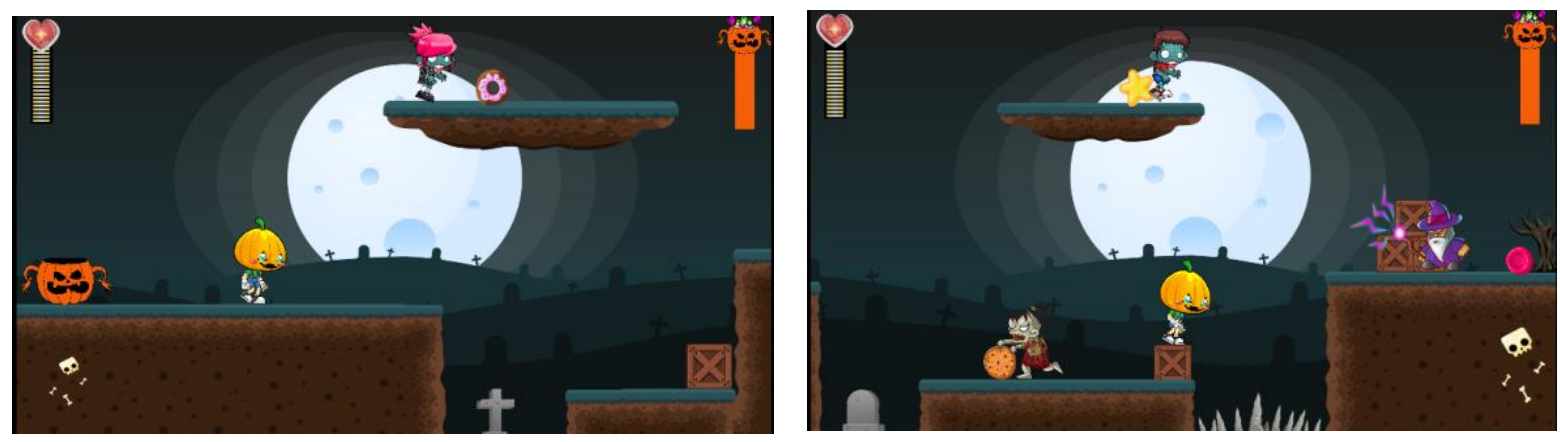

Figura 1. Cenário do jogo

O personagem principal é uma "cabeça de abóbora". Sua missão é recolher os doces que estão espalhados ao longo do cenário para depositar na grande abóbora de doces. Em relação aos inimigos, eles são representados por zumbis e bruxos, que tem a missão de proteger os doces. Os inimigos têm o poder de diminuir as vidas do personagem, caso os dois entrem em colisão. A principal motivação para o jogador é de controlar a movimentação do personagem principal (como andar, pular e pegar), considerando a necessidade de parar, esperar e pensar em estratégias que o ajude na coleta dos doces sob a ameaça dos inimigos e recursos do jogo. Essa dinâmica, quando associada ao controle inibitório, considera a importância do jogador desenvolver a capacidade de pensar, esperar ou inibir um comportamento antes de fazê-lo. A seção a seguir apresenta os objetivos de aprendizagem planejados para o seu desenvolvimento.

\subsection{Objetivos cognitivos do jogo}

De acordo com Tchounikine (2011), toda solução educativa é desenvolvida para atender objetivos. Para o autor, os objetivos de aprendizagem, também definidos como pedagógicos, podem ser categorizados em central (principal) e específicos (intermediários). Neste contexto, o principal objetivo do jogo é trabalhar a capacidade cognitiva de crianças que possuem inibição baixa ou controle inibitório, como 
habilidade cognitiva que obstrui a execução adequada das funções executivas. Para Lemes e Rossini (2014) o processo inibitório se caracteriza como a supressão de pensamentos, ações e emoções.

$\mathrm{Na}$ perspectiva do processo de aprendizagem, atender o objetivo principal do jogo requer considerar processos cognitivos como atenção, percepção e memória como estratégia para 1) minimizar comportamentos e/ou pensamentos impulsivos e imediatos, que possam atrapalhar a concentração necessária à aprendizagem; 2) inibir condutas e estímulos irrelevantes em situações em que atenção deve ser considerada para a realização de uma atividade; e 3) controlar a antecipação das ações e favorecer o planejamento delas. Isso significa que a proposta do jogo é promover mecanismos associados a ações como "parar, esperar e pensar" alinhado a eventos especiais do jogo (mais detalhes sobre os eventos são apresentados na seção 3.2), com o intuito de controlar os impulsos, planejar as ações e executá-las de maneira adequada em prol dos objetivos a serem atingidos.

Os objetivos pedagógicos do jogo refletem processos do domínio cognitivo. A cognição e seus processos cognitivos são amplamente discutidos nas áreas da Psicologia e Computação. Sob a perspectiva da Psicologia Cognitiva, estes processos mentais são ativados quando estamos realizando alguma atividade cotidiana (Barbosa e Silva, 2010), inclusive no ato de jogar. $\mathrm{Na}$ Computação, eles são discutidos na área de Interação Humano Computador (IHC) para atender a necessidade de utilizar estratégias cognitivas que proporcionem formas efetivas de aprendizagem e interação (Preece, Roger e Sharp, 2005). A Tabela 1 apresenta a descrição dos objetivos do jogo e sua relação com os processos cognitivos.

Tabela 1. Objetivos e processos cognitivos do jogo

\begin{tabular}{|c|l|l|}
\hline $\begin{array}{c}\text { Objetivos } \\
\text { cognitivos } \\
\text { (OC) }\end{array}$ & \multicolumn{1}{|c|}{ Descrição } & Processos \\
Cognitivos \\
\hline OC1 & $\begin{array}{l}\text { Lembrar e entender que os doces devem ser coletados e as } \\
\text { ações do personagem principal devem ser executadas } \\
\text { corretamente reconhecendo a importância de esperar o tempo } \\
\text { certo para acioná-las. }\end{array}$ & $\begin{array}{l}\text { Atenção e } \\
\text { Memória }\end{array}$ \\
\hline OC2 & $\begin{array}{l}\text { Aplicar estratégia de parar e esperar executando o planejamento } \\
\text { de movimentação do personagem em função da coleta dos } \\
\text { doces. }\end{array}$ & $\begin{array}{l}\text { Memória e } \\
\text { Percepção }\end{array}$ \\
\hline OC3 & $\begin{array}{l}\text { Analisar e avaliar a situação do jogo sob a perspectiva dos } \\
\text { bloqueios que impedem a coleta dos doces atribuindo as ações } \\
\text { adequadas para a movimentação do personagem. }\end{array}$ & Atenção \\
\hline
\end{tabular}

Os objetivos foram definidos conforme a taxonomia de Bloom revisada. A taxonomia de Bloom revisada é um esquema classificatório comumente adotado para formular e classificar os objetivos de aprendizagem de natureza intelectual (Ferraz e Belhot, 2010). Os objetivos são estruturados por verbos (de ação e gerúndio) e substantivo proposta em Krathwohl (2002). Como a proposta do jogo não é trabalhar a aprendizagem de conteúdo, os objetivos refletem comportamentos como ações 
impulsivas que podem ser inibidas, associadas ao controle do personagem principal. Detalhes da relação dos objetivos aos processos cognitivos é destacada na seção 3.4.

\subsection{Ludicidade}

Para Silva e Gomes (2015), a ludicidade é um fator que precisa ser considerado em jogos educativos porque estimula a aprendizagem. Nos jogos, a ludicidade representa "o ato de brincar" associados ao prazer e a diversão. De acordo com Huizinga (2001), os jogos possuem uma representação de alguma coisa como uma realidade paralela ao universo cotidiano. A ludicidade é, nesta perspectiva, um universo lúdico representado como um "círculo mágico", paralelo ao real, onde experiências e aprendizagens significativas podem ser consideradas. Mastrocola (2013) defende que o conceito de círculo mágico definido por Huizinga representa a possibilidade do jogador participar de um universo de diversão e uma vez que entra no círculo experimenta o que há lá dentro em termos de diversão, desafios, sonhos, narrativa, poderes, além da carga de experiência e aprendizado que pode carregar ao sair do jogo. No contexto do jogo, a ludicidade é representada pelos eventos especiais. Estes eventos representam eventos do mundo real assumidos de uma forma lúdica, no sentido de manter uma representação especial, diferente da realidade. A Tabela 2 reúne os eventos especiais do jogo, relacionado o que o jogador pode executar e quais as consequências de suas escolhas.

Tabela 2. Detalhes dos eventos especiais do jogo

\begin{tabular}{|c|c|c|}
\hline $\begin{array}{l}\text { Evento } \\
\text { Especial }\end{array}$ & Propósito & Consequências \\
\hline $\begin{array}{l}\text { Coletar } \\
\text { doces }\end{array}$ & $\begin{array}{l}\text { A coleta deve ser realizada de um } \\
\text { por um. }\end{array}$ & $\begin{array}{l}\text { O jogador só pode recolher um novo doce } \\
\text { quando depositar o que está em mãos. }\end{array}$ \\
\hline $\begin{array}{l}\text { Aguardar } \\
\text { Bloqueios }\end{array}$ & $\begin{array}{l}\text { Os bloqueios representam } \\
\text { impedimentos para o jogador coletar } \\
\text { os doces. Eles podem ser } \\
\text { representados por: a) serras: } \\
\text { espalhadas no caminho; b) grades: } \\
\text { dispostas em lugares fixos; c) } \\
\text { inimigos como zumbis e bruxos. }\end{array}$ & $\begin{array}{l}\text { a) O jogador deve esperar o momento certo } \\
\text { para passar a plataforma na qual a serra } \\
\text { está localizada; } \\
\text { b) Para poder continuar alguns trajetos, é } \\
\text { necessário que o jogador espere as } \\
\text { plataformas aparecerem; } \\
\text { c) O jogador deve esperar o zumbi sumir } \\
\text { para recolher os doces que estão } \\
\text { protegidos. Caso haja colisão entre eles, o } \\
\text { jogador perde vidas. }\end{array}$ \\
\hline $\begin{array}{l}\text { Ter } \\
\text { poderes }\end{array}$ & $\begin{array}{l}\text { Para garantir os poderes o jogador } \\
\text { deve esperar sobre a estrutura de cor } \\
\text { específica ao poder. O recurso só é } \\
\text { garantido quando o jogador aguarda } \\
\text { o elemento cair sobre ele: a) } \\
\text { imunidade: representado por uma } \\
\text { pipeta com antídoto azul; b) sorte: } \\
\text { representada por trevos de quatro } \\
\text { folhas; c) ação paralisar: } \\
\text { representada por um antídoto de cor } \\
\text { vermelha; d) vidas: representada por } \\
\text { corações. }\end{array}$ & $\begin{array}{l}\text { São recompensas que permitem ao jogador } \\
\text { realizar ações que o ajudam a combater os } \\
\text { inimigos e atingir o objetivo do jogo: } \\
\text { a) } \mathrm{O} \text { antídoto azul permite que o jogador } \\
\text { fique imune dos inimigos durante } 20 \\
\text { segundos; } \\
\text { b) O trevo permite que o jogador possa } \\
\text { escolher dois inimigos para que eles } \\
\text { desapareçam; } \\
\text { c) O antídoto vermelho faz com que os } \\
\text { inimigos fiquem paralisados por } 20 \\
\text { segundos; }\end{array}$ \\
\hline
\end{tabular}




\begin{tabular}{|l|l|l|}
\hline & & $\begin{array}{l}\text { d) O coração aumenta a barra de vida do } \\
\text { jogador. }\end{array}$ \\
\hline $\begin{array}{l}\text { Pegar } \\
\text { Chave }\end{array}$ & $\begin{array}{l}\text { Essa chave aparece ao longo do } \\
\text { cenário quando todos os doces são } \\
\text { recolhidos. }\end{array}$ & $\begin{array}{l}\text { Quando o jogador leva a chave até a porta o } \\
\text { jogo é concluído. }\end{array}$ \\
\hline
\end{tabular}

Os principais eventos especiais do jogo voltados para o controle inibitório estão associados aos bloqueios e no processo de obtenção dos poderes. No entanto, para garantir que os poderes possam ser usados, o jogador precisa entender a importância de aguardar, parar e inclusive pensar, planejando suas ações de movimentação do personagem em prol do alcance do objetivo. Isso significa que para garantir a quantidade de doces, o jogador é "forçado" a aguardar os bloqueios como ações do jogo que o impedem para tal.

\subsection{Processos cognitivos}

Para Araújo et al., processos cognitivos devem ser considerados no desenvolvimento de jogos educativos e podem ser ativados quando implicações de design adequadas são aplicadas na interface e alinhadas aos objetivos pedagógicos. Como as interfaces lúdicas promovem aprendizagem durante a interação, ativar os processos cognitivos requer aplicar recursos visuais e auditivos que possam favorecer a percepção, atenção e memória do usuário. De acordo com Preece, Rogers e Sharp (2005) o processo de atenção pode ser ativado com implicações de design que permitam que uma informação seja visível de forma a promover a concentração do usuário por um determinado tempo. A percepção pode ser favorecida com representações visuais claras e coerentes ao significado que deseja transmitir ao usuário. E, implicações para a memória, referem-se a estratégias para que o usuário possa reconhecer sua função e agir adequadamente. No contexto do Candy Night, estes três processos foram considerados para contribuir na impulsividade. A Tabela 3 relaciona os processos cognitivos aos eventos especiais e as implicações de design que favorecem sua ativação.

Tabela 3. Implicações de design para ativar processos cognitivos

\begin{tabular}{|l|l|l|}
\hline Processos & $\begin{array}{l}\text { Evento } \\
\text { Especial }\end{array}$ & \multicolumn{1}{c|}{ Implicação de Design } \\
\hline $\begin{array}{l}\text { Atenção e } \\
\text { Percepção }\end{array}$ & $\begin{array}{l}\text { Coleta } \\
\text { dos } \\
\text { doces }\end{array}$ & $\begin{array}{l}\text { O som "HAHAHA" é emitido quando o jogador deposita o doce na } \\
\text { abóbora. O jogador pode perceber que a barra dos doces é alimentada e } \\
\text { assim considerar a quantidade restante de doces que precisa recolher. A } \\
\text { barra de doce sobe cada vez que um doce é entregue a abóbora, assim } \\
\text { ficando perceptível para o jogador a quantidade de doce que falta } \\
\text { recolher. }\end{array}$ \\
\hline Memória & $\begin{array}{l}\text { Ter } \\
\text { Poderes }\end{array}$ & $\begin{array}{l}\text { Os signos da "Pipeta do antídoto, trevo de quatro folhas, serra, zumbis, } \\
\text { entre outros imagens favorecem o processo de recordação sobre sua } \\
\text { função no jogo. Uma vez processada e memorizada a informação, o } \\
\text { jogador consegue agir adequadamente. }\end{array}$ \\
\hline Percepção & Tempo & $\begin{array}{l}\text { A representação de um relógio é apresentada para ativar poderes em que } \\
\text { o tempo é necessário. Esta representação indica a duração do poder e }\end{array}$ \\
\hline
\end{tabular}




\begin{tabular}{|l|l|}
\hline & $\begin{array}{l}\text { serve para o jogador se orientar e agir de forma estratégica. Os poderes } \\
\text { de tempo estão associados a imunidade. }\end{array}$ \\
\hline
\end{tabular}

As imagens que compõem o cenário, os recursos e personagens têm impacto direto com o objetivo do jogo, quando classificadas corretamente em relação ao seu efeito e a função. De acordo com Reategui (2007), as ilustrações em interfaces educativas podem manter o efeito de elaboração ou motivação, além das funções (decorativa, representativa, organizacional e explanatória) como estratégia para promover a aprendizagem. Estes fatores são importantes porque uma interface educativa não atraente impacta diretamente no processo de interação e aprendizagem.

O poder explicativo das imagens é garantido quando efeitos e funções associadas a elas geram aprendizagem, favorecendo a percepção e interpretação do usuário enquanto joga. Diante deste contexto, entende-se que classificar as imagens pode ser uma alternativa que também contribua para a ativação dos processos cognitivos. No geral, as imagens adotadas no jogo possuem o efeito de motivação. Este efeito define que a imagem incentiva o usuário a realizar uma ação no jogo como um "impulso". No jogo, as imagens que representam este efeito, em sua maioria, estão relacionadas aos poderes. A Figura 2 destaca que os elementos antídoto, pipeta vermelha, trevo e cápsula de gelo possuem o efeito de motivação porque impulsionam o jogador a permanecer sobre a estrutura para conseguir obtê-los (a). A imagem da abóbora também possui o efeito de motivação (b), é nela que os doces devem ser depositados para assim o jogador alcançar o objetivo.

Por sua vez, em relação à função, as imagens dos elementos possuem a função explanatória. De acordo com Reategui (2007), esta função deve ser usada para explicar o funcionamento de um sistema dinâmico, no qual a variável tempo é considerada. Neste caso, obter os elementos depende do jogador, no sentido de aguardar que o recurso possa cair sobre sua cabeça. Foi definido que estes elementos teriam um tempo para ser obtido e caso o jogador saia de cima da estrutura, o elemento a ser obtido para de cair e fica inativo até que ele retorne ao posicionamento da estrutura e espere o elemento cair.

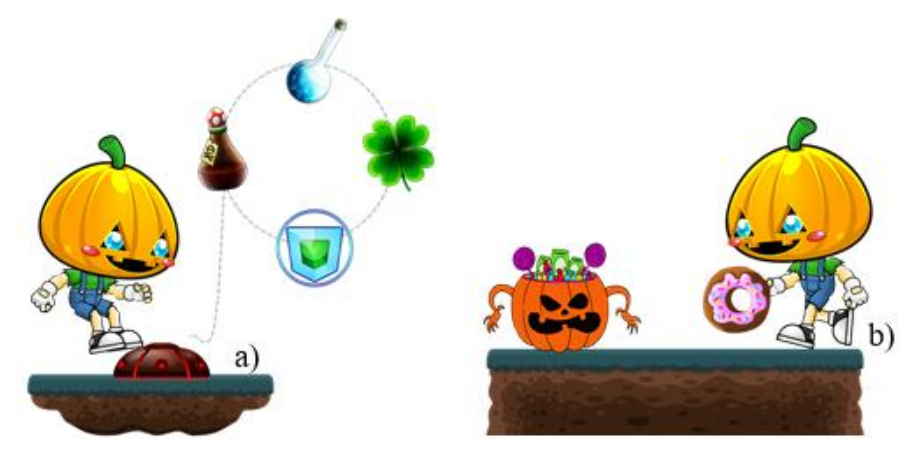

Figura 2. Efeitos das imagens adotadas no jogo

\section{Considerações Finais}

Desenvolver soluções educativas é desafiador porque requer um processo com etapas bem definidas e uma equipe multidisciplinar com diferentes perspectivas. Para a Psicologia, além dos transtornos de aprendizagem, a educação precisa considerar, no desenvolvimento humano, os aprimoramentos da FE para quaisquer pessoas, sob riscos 
de se criar situações que estimulem o surgimento de dificuldades de aprendizagem. Por sua vez, a Computação enxerga problemas como este para conceber soluções educativas que possam melhorar o contexto da aprendizagem.

Mesmo que os jogos estão cada vez mais adotados para este contexto, percebeuse que, jogos especificamente sobre o controle inibitório são poucos concebidos. Neste caso, esta pesquisa contribui para o processo de desenvolvimento de jogos sob a perspectiva de interação com ludicidade. A ideia é reforçar a importância das interfaces, por considerar representações e implicações adequadas para ativar os processos cognitivos desejados. Como trabalhos futuros, espera-se planejar e executar aplicações do jogo em situações reais para verificar sua utilidade sob a verificação dos objetivos cognitivos.

\section{Referências}

Araújo, D.; Rodrigues, A.; Lacerda, P.; Dionísio, M.; Santos, H. (2016) "Processo de desenvolvimento do jogo sério Missão Aedes: relações entre objetivos pedagógicos, ludicidade e implicações de design". Anais do SBIE.

Baum, C.; Maraschin, C. Level up! desenvolvimento cognitivo, aprendizagem enativa e videogames. Psicol. Soc., Belo Horizonte, v. 29, e132334, 2017.

Barbosa, S. D. J.; Silva, B. S. (2010) "Interação Humano-Computador”. Editora Campus-Elsevier.

Cerqueira, B. B.; Barbosa, D. N. F. e Mossmann, J. B. (2018). "Revisão Exploratória de Literatura em Jogos Digitais voltados para estimulação do Controle Inibitório em Crianças do Ensino Fundamental". Revista Conhecimento Online. Ed. especial: Out. 2018, a. 10 , v. 3.

Cunha, E. O., Dazzani, M. V. M., Santos, F. L. and Zucoloto, P. C. S. do V. (2016). "A queixa escolar sob a ótica de diferentes atores: análise da dinâmica de sua produção". Estudos de Psicologia, Vol.33 no 2, 237-245.

Ferraz, A. P. do C. M.; Belhot, R. V. (2010) Taxonomia de Bloom: revisão teórica e apresentação das adequações do instrumento para definição de objetivos instrucionais. Gest. Prod., São Carlos, v. 17, n. 2, p. 421-431, 2010.

Freire, J. V. S.; Costa, A. D.; Silva, A. G. F. e Kneipp, R. E. (2018). "Digital Game Based Learning e transtornos que afetam o aprendizado". Sociedade Brasileira de Computação (SBC) - Proceedings of SBGames 2018.

Huizinga, J. (2001) "Homo ludens". São Paulo: Perspectiva.

Kandel, E.R; Schwartz, J.H.; Jessel, T.M. Princípios da neurociência. São Paulo:

Manole, 2003.

Krathwohl, D. R. (2002) “A Revision of Bloom's Taxonomy: An Overview. Theory into Practice", vol.4. College of Educacion, The Ohio State University.

Malloy-Diniz, L. F. et al. (2012). Neuropsicologia das funções executivas. In: Caixeta, L.; Ferreira, S.B. (Org.). Manual de neuropsicologia: dos princípios á reabilitação. São Paulo: Atheneu, p.27-44. 
Malloy-Diniz, L. F., Fuentes, D., Mattos, P., \& Abreu, N. (2010). "Avaliação Neuropsicológica". Porto Alegre: Artmed.

Mastrocola, V. M. (2013) "Doses lúdicas: breves textos sobre o universo dos jogos e entretenimento". / Vicente Martin Mastrocola. - São Paulo: Independente.

Preece, J.; Rogers,; Sharp, H. (2005) "Design de interação: além da interação homemcomputador", Bookman.

Ramos, D. K. e Anastácio, B. S. (2018). "Habilidades cognitivas e o uso de jogos digitais na escola: a percepção das crianças ${ }^{1 "}$. Revista: Educação Unisinos. Editora: Universidade do Vale do Rio dos Sinos.

Ramos, D. K. e Rocha, N. L. (2016). "Avaliação do uso de jogos eletrônicos para o aprimoramento das funções executivas no contexto escolar". Revista psicopedagogia, vol.33 no.101 - São Paulo.

Reategui, E. (2007) "Interfaces para softwares educativos". Revista Novas Tecnologias na Educação, v.5, n.1, pág. 1-10.

Seabra, A. G.; Laros, J. A.; Macedo, E. C. and Abreu, N. (2014). "Inteligência e Funções Executivas: Avanços e Desafios para a Avaliação Neuropsicológica". São Paulo: Memnon, p. 39-50. 2014.

Sternberg, R.J. Psicologia cognitiva. São Paulo: Cengage Learning, 2002.

Silva, A. C. B da; Gomes, A. S. (2015) Conheça e utilize software educativo: avaliação e planejamento para a educação básica Série Professor Criativo - Volume 2.

Tchounikine, P. (2011) "Computer Science and Educational Software Design. A resource for Multidisciplinary Work in Technology Enhanced Learning”. 